\title{
Neuroprotective Effects of Physical Activity: Evidence from Human and Animal Studies
}

\begin{abstract}
Sergio Chieffi ${ }^{1 \dagger}$, Giovanni Messina ${ }^{1,2 *}$, Ines Villano ${ }^{1}$, Antonietta Messina ${ }^{1}$, Anna Valenzano ${ }^{2}$, Fiorenzo Moscatelli ${ }^{2}$, Monica Salerno ${ }^{2}$, Alessio Sullo', Roberto Avola ${ }^{3}$, Vincenzo Monda', Giuseppe Cibelli ${ }^{2}$ and Marcellino Monda ${ }^{1}$
\end{abstract}

\begin{abstract}
'Department of Experimental Medicine, Università degli Studi della Campania "Luigi Vanvitelli", Naples, Italy, ${ }^{2}$ Department of Clinical and Experimental Medicine, University of Foggia, Foggia, Italy, ${ }^{3}$ Department of Biomedical and Biotechnological Sciences, University of Catania, Catania, Italy
\end{abstract}

In the present article, we provide a review of current knowledge regarding the role played by physical activity $(\mathrm{PA})$ in preventing age-related cognitive decline and reducing risk of dementia. The cognitive benefits of PA are highlighted by epidemiological, neuroimaging and behavioral studies. Epidemiological studies identified PA as an influential lifestyle factor in predicting rates of cognitive decline. Individuals physically active from midlife show a reduced later risk of cognitive impairment. Neuroimaging studies documented attenuation of age-related brain atrophy, and also increase of gray matter and white matter of brain areas, including frontal and temporal lobes. These structural changes are often associated with improved cognitive performance. Importantly, the brain regions that benefit from PA are also those regions that are often reported to be severely affected in dementia. Animal model studies provided significant information about biomechanisms that support exercise-enhanced neuroplasticity, such as angiogenesis and upregulation of growth factors. Among the growth factors, the brain-derived neurotrophic factor seems to play a significant role. Another putative factor that might contribute to beneficial effects of exercise is the neuropeptide orexin-A. The beneficial effects of PA may represent an important resource to hinder the cognitive decline associated with aging.

Keywords: physical activity and wellbeing, hippocampus, neurogenesis, growth factors, orexins

\section{INTRODUCTION}

Clinical and epidemiological studies suggest that the physical activity (PA) can play an important and positive role in the prevention and treatment of age-related cognitive decline, as well as of a range of medical conditions, including type II diabetes, hypertension, heart disease, stroke, osteoporosis, cancers, and obesity. In support of the beneficial effects of PA on cognitive performance, there are a number of epidemiological, behavioral, and neuroimaging studies.

Physical activity was identified as an influential lifestyle factor in predicting rates of cognitive decline $(1,2)$ and the subsequent development of age-related neurodegenerative diseases such as Alzheimer's disease $(\mathrm{AD})(3,4)$. Women who reported being physically active at any point over the life course, especially as teenagers, showed a lower likelihood of cognitive impairment in late life (1). Yaffe et al. (2) performed an interesting prospective study in which cognitive function of an older adult population was measured at baseline and subsequently. Over 8 years, $30 \%$ of the participants maintained cognitive function, $53 \%$ showed minor decline, and $16 \%$ had major cognitive decline. 
The authors (2) found that maintainers were more likely to engage in moderate to vigorous exercise compared to cognitive decliners. Neuroprotective effects of PA were also found by Larson et al. (5). They (5) followed a cohort of older adults ( $>65$ years) over 6 years and found that regular exercise is associated with a delay in onset of dementia and $\mathrm{AD}$. In particular, they reported a reduced incidence rate of dementia for persons who exercised three or more times a week compared with those who exercised fewer than three times per week. Subsequently, Buchman et al. (6) employed actigraphy to obtain an objective measure of total daily PA, circumventing in this way recall bias associated with traditional PA questionnaires. In the study (6) participated older adults [81.6 (7.12) years] who were followed for an average of 3.5 years. Participants in the lowest PA percentiles (10th percentile) had more than twofold higher risk of developing $\mathrm{AD}$ as compared to participants in the highest PA percentiles (90th percentile). Finally, two significant meta-analyses examined the association between PA and risk of dementia and found that PA was inversely associated with risk of dementia $(3,4)$.

Several neuroimaging studies also suggested a protective role of PA in preventing age-related decline related to brain atrophy. Comparing MRI images of older adults (60-79 years) collected before and after a 6-month aerobic fitness intervention, Colcombe et al. (7) observed significant increases in both gray matter and white matter (GM and WM) volumes as a function of fitness training. Interestingly, the increase of brain tissue volumes was primarily located in prefrontal and temporal cortices (7). In a subsequent research, Erickson and colleagues $(8,9)$ demonstrated that highly fit or aerobically trained participants showed preservation and increase of volume of the hippocampus, located in the inner (medial) region of the temporal lobe, and better performance on the spatial memory. Erickson et al. (9) reported an increase of the anterior hippocampus volume by $2 \%$ in older adults who followed 1 -year aerobic exercise training, whereas there was a $1.4 \%$ decline in the control group that followed 1-year stretching intervention. This decline is comparable to the $1-2 \%$ shrinkage of hippocampus volume that was reported occurring annually in older adults (10). Other researches showed that increases in total PA were positively associated with increases in local GM volume in prefrontal and cingulate cortex (11) and greater WM integrity in the frontal and temporal lobes (12). Two interesting follow-up studies provided further support of a protective effect of PA against agerelated decline $(13,14)$. In older adults $(65$ years old and older at baseline), greater amounts of PA were associated 9 years later with greater GM volume in prefrontal and temporal regions, including the hippocampus and entorhinal cortex (13). In turns, greater GM volume was related to a lower risk for experiencing cognitive impairment (13). In another study, participants were studied in midlife (early fifties) and re-examined on average 21 years later (14). Individuals who actively participated in PA at midlife tended to have larger total brain and GM volume, especially at level of the frontal lobes, in late life than sedentary persons (14). Rovio et al. (14) suggested that PA by activating the motor cortex localized in the frontal lobe also activated frontal structures related to cognitive functions, decreasing in this way the risk of dementia. Colcombe and Kramer (15) conducted an interesting meta-analytic study to examine the relationship between aerobic fitness training and cognition in healthy but sedentary older adults. They (15) found that fitness training had robust but selective benefits for cognition, with the largest benefits occurring for executive control processes. Some factors influenced the efficacy of the treatment: training duration (long-term training programs yield larger effect sizes); session duration within the training period (sessions exceeding 30 min had larger effect sizes); and the combination of strength and aerobic training regimens were more effective than aerobic exercise alone (15).

Then, the studies we have reported show that the frontal region is one of the brain regions that get more benefit from PA. Frontal areas subserve critical executive control processes, including the inhibition of irrelevant information (16-20). Flanker (21) and Stroop (22) tasks, and Digit Symbol Substitution Test (23) were employed to examine whether PA enhanced the ability in inhibiting irrelevant information in older adults. In the flanker task, participants were asked to respond to the direction of the central arrow while ignoring the two flanking arrows on either side (21); in the Stroop task, to respond manually to the color of ink in which the word was printed, rather than responding to the semantic meaning of the word (22); in the DDS, to match a number-symbol pair (probe) to a previously showed number-symbol pair (cue) (23). Highly fit or aerobically trained participants showed a better behavioral performance and greater task-related activity in prefrontal and parietal cortices, i.e., in regions consistently implicated in attentional selection and the resolution of response conflict.

\section{MILD COGNITIVE IMPAIRMENT (MCI) AND AD}

The studies reported above support the view that PA seems not only to spare brain volume but also increase both GM and WM mainly in the prefrontal and temporal cortices. These brain areas play a critical role in cognitive functions. Prefrontal regions are associated with working memory and executive functions (24-28) and temporal lobes with long-term memory function (29-31). Interestingly, these regions are also those same regions that are often reported to deteriorate with aging $(7,23)$ and be severely affected in $\operatorname{AD}(32,33)$.

Experimental evidence suggests a positive effect of aerobic exercise training on cognitive function in MCI and AD populations. MCI is a potential transitional stage between normal cognitive function and $\mathrm{AD}$ (34). MCI patients experience mainly memory loss to a greater extent than is expected for age and education, but do not meet criteria for AD (34). Two studies investigated the effects on cognitive performance of a 6-month aerobic exercise training in MCI participants $(35,36)$. Baker et al. (35) found that aerobic exercise had beneficial effects on cognitive performance of amnestic MCI participants (55-85 years). However, women improved on multiple tests of executive function, men only on a single test. Only women (70-80 years) with probable MCI participated to the study of Nagamatsu et al. (36). 
They showed an improvement of verbal memory and spatial memory. In another study, MCI (70-80 years) individuals participated to 1 year of a moderate-intensity aerobic walking program (37). The walking program was efficacious in improving memory and attention in women and memory in men, but only in those with better adherence (37).

Alzheimer's disease is considered a neurodegenerative disease that brings about a variety of cognitive disorders and motor perturbations. In $\mathrm{AD}$, subsequent to the loss of memory, the deficits carry over into the areas of language (aphasia), motion organization (apraxia), visual recognition (agnosia), and the executive functions (38). Also in the case of AD, several studies lend support for neuroprotective effects of PA. In the Kemoun et al.s study (39), AD participants [81.8 (5.3) years] benefited from a 15-week PA program. There was an improvement in cognitive capacities and walking capacities (39). Conversely, the AD control group who did not practice any PA showed a deterioration of cognitive functions and walking capacities (39). In the study by Yágüez et al. (40), AD individuals [70.5 (8) years] who received 6-week exercise intervention showed significant improvements in sustained attention, visual memory, and a trend in working memory, whereas the $\mathrm{AD}$ control group deteriorated significantly in attention. Interestingly, PA seems to exert a beneficial effect on the hippocampus, a brain region particularly sensitive to age-related decay (9). Hippocampus shrinks with age (10) and its atrophy predicts shorter time-to-progression from MCI to AD (41). Erickson et al. (9) found an increase of anterior hippocampus size and better spatial memory performance with aerobic exercise intervention in older adults. Gains in hippocampal blood flow and memory performance were also observed by Chapman et al. (42) in healthy sedentary adults (57-75 years) with shorter term exercise (3 months).

\section{ANIMAL STUDIES: HIPPOCAMPAL NEUROGENESIS}

Since the approach of human neuroscience is basically noninvasive, it does not allow direct measurement of exercise effects on the brain at the cellular and molecular level. To overcome this limitation, research employs animal models. In this context, the study of hippocampal changes produced by exercise attracted the interest of many research groups mainly for two reasons. First, as stated above, the hippocampus is a region sensitive to the beneficial effects of PA, but at the same time it is particularly vulnerable to age-related decay $(7,23)$. Note that the hippocampus is critically involved in memory processes $(29,30)$. Second, the hippocampus, along with the olfactory bulb, is the place in the adult in which new neurons are generated throughout life (43). Therefore, it is very important to accurately define the cellular and molecular mechanisms that support hippocampal neurogenesis. Some factors have been identified that seem to favor neurogenesis, including environmental enrichment, voluntary exercise, and associative learning (44-46). Early studies showed that the exposure to enriched environment increased neurogenesis in the dentate gyrus and improved also spatial memory performance of adult rodents $(47,48)$. However, in the enriched environment, more factors might contribute to enhance the neurogenesis, e.g., social, cognitive, and physical stimulations. van Praag et al. (44) tried to define the relative importance of some of these factors. They (44) assigned adult mice to various conditions, including enriched and standard housing, and voluntary and forced exercise. van Praag et al. (44) observed that voluntary exercise doubled the number of surviving newborn cells in amounts similar to enrichment condition. The authors (44) proposed that voluntary exercise was sufficient for enhanced neurogenesis in the adult mouse dentate gyrus. Hippocampal neurogenesis diminishes with aging (49), but this decrease may be partially opposed by exercise (46). Exercise-enhanced hippocampal neurogenesis and learning in aged mice (46). Interestingly, the morphology of new neurons did not differ between young and aged runners, suggesting that local hippocampal environment of the aged dentate gyrus is effective in sustaining neurogenesis (46).

A different line of research investigated the effects of hyppocampal lesion on behavioral performance. Clark et al. (50) irradiated with gamma rays the region of mice hippocampus reducing neurogenesis by $50 \%$. The authors (50) observed that in non-irradiated animals running increased neurogenesis fourfold and gains in performance for the Morris water maze (spatial learning and memory), rotarod (motor performance), and contextual fear (conditioning). Conversely, irradiation, besides reducing neurogenesis, selectively eliminated gains in water maze performance that depends on hippocampus. The decrease in neurogenesis and cognitive skills, induced by irradiation, might be mitigated by exercise. Rats that received whole-brain irradiation and, following irradiation, were forced to perform exercise showed a significant amelioration of the impaired neurogenesis and cognition (51).

The morphological and functional changes in hippocampus produced by exercise likely depend on the contribution of different factors, including the enhancement of vascularization and upregulation of growth factors.

\section{ANGIOGENESIS}

Experimental evidence suggests that exercise increases angiogenesis (i.e., the growth of new blood vessels) in the hippocampus (46) and angiogenesis is closely linked to hippocampal neurogenesis (52). In a seminal study, Pereira et al. (52) used MRI imaging to measure cerebral blood changes related to exercise in mice and humans. Note that some studies reported the existence of a tight relationship in the brain between regional blood volume and angiogenesis (53). Pereira et al. (52) observed that in mice cerebral blood volume increased with exercise and presented a positive correlation with newly born cells (52). Also in humans (21-45 years) who participated to a 12-week exercise training, there was a significant increase of hippocampal dentate gyrus blood volume over baseline (52). Pereira et al. (52) proposed that the increase of hippocampal blood volume might be considered an in vivo correlate of neurogenesis.

\section{GROWTH FACTORS}

Exercise upregulates expression of growth factors including brain-derived neurotrophic factor (BDNF), vascular endothelial 
growth factor (VEGF), and insulin-like growth factor-1 (IGF-1) $(54,55)$. Among these, the BDNF is considered to be the most important factor. A lot of studies suggest that the upregulation of BDNF plays a significant role in hippocampal neurogenesis, dendritic complexity, and synaptic plasticity $(44-46,56)$. Importantly, these structural changes in the hippocampus appeared associated with improved spatial learning and memory $(44-46,50,57)$. Note that BDNF levels in serum and plasma are highly correlated with BDNF levels in the central nervous system, as BDNF freely crosses the blood-brain barrier (58). In humans, more researches reported that exercise increased BDNF concentrations serum suggesting a key role for this neurotrophic factor in enhancing hippocampal volume and cognitive function $(9,59,60)$. Interestingly, circulating BDNF levels were reduced in patients with $\mathrm{AD}(61,62)$. Furthermore, $\mathrm{AD}$ patients whose condition was rapidly declining have significantly lower serum BDNF concentrations than those whose condition was slowly declining $(61,63)$.

Angiogenesis factors, especially VEGF, are now known to have roles in neurogenesis and neuroprotection (64). Fabel et al. (65) showed that peripheral vascular endothelial VEGF is necessary for the effects of running on adult hippocampal neurogenesis. Peripheral blockade of VEGF abolished running-induced neurogenesis but had no detectable effect on baseline neurogenesis in non-running animals (65).

Exercise also increases the levels of IGF-1 in several brain structures, including the rat hippocampus (66). In aged rodents, circulating IGF-1 levels decrease (67). An increase of IGF-1 with exercise has been also reported in humans (68). Note that IGF-1 can cross (69) and increased levels of circulating IGF-1 result in increased IGF-1 levels in the brain (66). Blocking the entrance of circulating IGF-1 into the brain followed a complete inhibition of exercise-induced neurogesis in the hippocampus (70). A meta-analysis revealed a highly significant positive association between IGF-I levels and cognitive functioning in older adults (71). Patients with AD had significantly lower circulating IGF-1 levels than controls, and these levels were inversely correlated with cognitive impairment (72).

\section{OREXIN-A AND OREXIN-B}

Another factor that acting on the hippocampus might contribute to the beneficial effects of physical exercise on cognition is the orexin-A. The orexin-A/hypocretin-1 (OxA/Hcrt-1) and orexin$\mathrm{B} /$ hypocretin-2 (OxB/Hcrt-2) are neuropeptides synthesized by a cluster of neurons in the lateral hypothalamus $(73,74)$. Orexins selectively act on two $\mathrm{G}$ protein-coupled receptors: the orexin 1 receptor $(\mathrm{Ox} 1 \mathrm{R})$, which has higher affinity to OxA, and the orexin 2 receptor $(\mathrm{Ox} 2 \mathrm{R})$, which has equal affinity to both $\mathrm{OxA}$ and $\mathrm{OxB}$ $(73,74)$. Ox1R and $\mathrm{Ox} 2 \mathrm{R}$ are generally excitatory and mediate both acute and long-lasting effects (74). Orexinergic neurons receive a variety of signals related to environmental, physiological, and emotional stimuli and project broadly to the entire CNS (75). Orexinergic system is involved in regulating wakefulness and arousal, motivation and emotions, and motor and autonomic functions (76-84). Furthermore, orexinergic system may induce structural changes in the hippocampus influencing hippocampal learning and memory processes. Local dentate gyrus perfusion with OxA enhanced long-term potentiation (LTP) in anesthetized rats, suggesting that orexins positively regulated hippocampal synaptic plasticity (85). Conversely, the pretreatment with SB-334867, a specific Ox1R antagonist, blocked LTP (85) and impaired spatial memory in Morris water maze (86). In rats treated with Pentylenetetrazol that induces hippocampal atrophy and spatial learning and memory deficits, the administration of OxA enhanced hippocampal neurogenesis and attenuated learning and memory deficits (87).

Physical exercise produces an increase of OxA level in cerebrospinal fluid of rats (88), dogs (89), and cats (90). An increase of plasmatic OxA with exercise was reported in humans (91-95). The source of peripheral orexins is still unclear. Tsunematsu and Yamanaka (96) proposed that OxA might be directly released from the pituitary into the blood stream, or leaked from the cerebrospinal fluid, or produced by peripheral tissues, e.g., gastrointestinal tract and pancreas. Interestingly, OxA may rapidly cross the blood-brain barrier highly lipophilic (97). Taken together, the experimental data we have reported allow to hypothesize that the increase of OxA levels with exercise might contribute to improve cognition, enhancing hippocampal plasticity and function.

\section{CONCLUSION}

In this review are discussed researches that support the view that PA is an effective tool for attenuating cognitive decline related to aging. PA would induce both morphological and functional changes of those regions that play central roles in successful everyday functioning, such as frontal and temporal cortices. In particular, exercise-induced hippocampal changes have attracted the interest of many researchers since the hippocampus, along with the olfactory bulb, is the place in the adult in which mammalian brain continues to generate new neurons throughout life. A better microcirculation and increased levels of growth factors seem to contribute to hippocampal neurogenesis. Another putative factor that might contribute to the beneficial effects of PA is the OxA. In favor of this hypothesis, there are the following observations: (1) hypothalamic orexinergic neurons have connections to hippocampus; (2) OxA enhances hippocampal neurogenesis and functions; and (3) OxA levels increase with exercise.

The regions that benefit from PA are also those that seem more vulnerable to aging, loading to a decline in a broad array of cognitive processes. In this context, PA may constitute a promising support for a neuroprotective effect against cognitive decline in $\mathrm{MCI}$ and $\mathrm{AD}$. This is very important if we consider the continuous and progressive increase in the number of adults surviving to advanced age, and consequently the significant increase of health problems. Dementia represents the major threat of aging decline resulting in a considerable worsening of life quality not only of the patients but also of their family members, and in a dramatic increase of healthcare service costs. In this context, the PA may represent a simple, but effective and low cost, therapeutic intervention to improve neurocognitive functions. PA is accessible to 
most older adults and is not plagued by intolerable side effects that often occur with pharmaceutical treatments.

\section{AUTHOR CONTRIBUTIONS}

$\mathrm{IV}, \mathrm{AM}$, and $\mathrm{AV}$ : conceived the study, participated in its design, and wrote the manuscript. FM, MS, AS, RA, and VM: contributed to the conception and design of the study. SC, GC, MM, and GM: drafted the article and revised it critically for

\section{REFERENCES}

1. Middleton LE, Barnes DE, Lui LY, Yaffe K. Physical activity over the life course and its association with cognitive performance and impairment in old age. J Am Geriatr Soc (2010) 58:1322-6. doi:10.1111/j.1532-5415. 2010.02903.x

2. Yaffe K, Fiocco AJ, Lindquist K, VittinghoffE, SimonsickEM, Newman AB, et al. Predictors of maintaining cognitive function in older adults: the Health ABC study. Neurology (2009) 72:2029-35. doi:10.1212/WNL.0b013e3181a92c36

3. Hamer M, Chida Y. Physical activity and risk of neurodegenerative disease: a systematic review of prospective evidence. Psychol Med (2009) 39:3-11. doi:10.1017/S0033291708003681

4. Sofi F, Valecchi D, Bacci D, Abbate R, Gensini GF, Casini A, et al. Physical activity and risk of cognitive decline: a meta-analysis of prospective studies. J Intern Med (2011) 269:107-17. doi:10.1111/j.1365-2796.2010.02281.x

5. Larson EB, Wang L, Bowen JD, McCormick WC, Teri L, Crane P, et al. Exercise is associated with reduced risk for incident dementia among persons 65 years of age and older. Ann Intern Med (2006) 144:73-81. doi:10.7326/ 0003-4819-144-2-200601170-00004

6. Buchman AS, Boyle PA, Yu L, Shah RC, Wilson RS, Bennett DA. Total daily physical activity and the risk of $\mathrm{AD}$ and cognitive decline in older adults. Neurology (2012) 78:1323-9. doi:10.1212/WNL.0b013e3182535d35

7. Colcombe SJ, Erickson KI, Scalf PE, Kim JS, Prakash R, McAuley E, et al. Aerobic exercise training increases brain volume in aging humans. J Gerontol A Biol Sci Med Sci (2006) 61:1166-70. doi:10.1093/gerona/61.11.1166

8. Erickson KI, Prakash RS, Voss MW, Chaddock L, Hu L, Morris KS, et al. Aerobic fitness is associated with hippocampal volume in elderly humans. Hippocampus (2009) 19:1030-9. doi:10.1002/hipo.20547

9. Erickson KI, Voss MW, Prakash RS, Basak C, Szabo A, Chaddock L, et al. Exercise training increases size of hippocampus and improves memory. Proc Natl Acad Sci U S A (2011) 108:3017-22. doi:10.1073/pnas.1015950108

10. Raz N, Lindenberger U, Rodrigue KM, Kennedy KM, Head D, Williamson A, et al. Regional brain changes in aging healthy adults: general trends, individual differences and modifiers. Cereb Cortex (2005) 15:1676-89. doi:10.1093/ cercor/bhi044

11. Ruscheweyh R, Willemer C, Kruger K, Duning T, Warnecke T, Sommer J, et al. Physical activity and memory functions: an interventional study. Neurobiol Aging (2011) 32:1304-19. doi:10.1016/j.neurobiolaging.2009.08.001

12. Voss MW, Heo S, Prakash RS, Erickson KI, Alves H, Chaddock L, et al. The influence of aerobic fitness on cerebral white matter integrity and cognitive function in older adults: results of a one-year exercise intervention. Hum Brain Mapp (2013) 34:2972-85. doi:10.1002/hbm.22119

13. Erickson KI, Raji CA, Lopez OL, Becker JT, Rosano C, Newman AB, et al. Physical activity predicts gray matter volume in late adulthood: the Cardiovascular Health Study. Neurology (2010) 75:1415-22. doi:10.1212/WNL. 0b013e3181f88359

14. Rovio S, Spulber G, Nieminen LJ, Niskanen E, Winblad B, Tuomilehto J, et al. The effect of midlife physical activity on structural brain changes in the elderly. Neurobiol Aging (2010) 31:1927-36. doi:10.1016/j.neurobiolaging.2008.10.007

15. Colcombe SJ, Kramer AF. Fitness effects on the cognitive function of older adults: a meta-analytic study. Psychol Sci (2003) 14:125-30. doi:10.1111/14679280.t01-1-01430

16. Godefroy O, Jeannerod M, Allain P, Le Gall D. Frontal lobe, executive functions and cognitive control. Rev Neurol (Paris) (2008) 164(Suppl 3):S119-27. doi:10.1016/S0035-3787(08)73302-2 important intellectual content. GM: gave final approval of the version to be published. All authors read and approved the final manuscript.

\section{FUNDING}

This review was financially supported by Section of Human Physiology and Unit of Dietetic and Sport Medicine, Università degli Studi della Campania "Luigi Vanvitelli."

17. Chieffi S, Iavarone A, Viggiano A, Monda M, Carlomagno S. Effect of a visual distractor on line bisection. Exp Brain Res (2012) 219:489-98. doi:10.1007/ s00221-012-3106-8

18. Chieffi S, Iachini T, Iavarone A, Messina G, Viggiano A, Monda M. Flanker interference effects in a line bisection task. Exp Brain Res (2014) 232:1327-34. doi:10.1007/s00221-014-3851-y

19. Chieffi S, Iavarone A, Iaccarino L, La Marra M, Messina G, De Luca V, et al. Age-related differences in distractor interference on line bisection. Exp Brain Res (2014) 232:3659-64. doi:10.1007/s00221-014-4056-0

20. Chieffi S, Iavarone A, La Marra M, Messina G, Dalia C, Viggiano A, et al. Vulnerability to distraction in schizophrenia. J Psychiatry (2015) 18:228. doi:10.4172/Psychiatry.1000228

21. Colcombe SJ, Kramer AF, Erickson KI, Scalf P, McAuley E, Cohen NJ, et al. Cardiovascular fitness, cortical plasticity, and aging. Proc Natl Acad Sci U S A (2004) 101:3316-21. doi:10.1073/pnas.0400266101

22. Prakash RS, Voss MW, Erickson KI, Lewis JM, Chaddock L, Malkowski E, et al. Cardiorespiratory fitness and attentional control in the aging brain. Front Hum Neurosci (2011) 4:229. doi:10.3389/fnhum.2010.00229

23. Rosano C, Venkatraman VK, Guralnik J, Newman AB, Glynn NW, Launer L, et al. Psychomotor speed and functional brain MRI 2 years after completing a physical activity treatment. J Gerontol A Biol Sci Med Sci (2010) 65:639-47. doi:10.1093/gerona/glq038

24. Chieffi S, Conson M, Carlomagno S. Movement velocity effects on kinaesthetic localisation of spatial positions. Exp Brain Res (2004) 158:421-6. doi:10.1007/ s00221-004-1916-z

25. Chieffi S, Iavarone A, Carlomagno S. Effects of spatiotopic factors on bisection of radial lines. Exp Brain Res (2008) 189:129-32. doi:10.1007/ s00221-008-1458-x

26. Chieffi S, Secchi C, Gentilucci M. Deictic word and gesture production: their interaction. Behav Brain Res (2009) 203:200-6. doi:10.1016/j.bbr.2009. 05.003

27. Chieffi S. Visual illusion and line bisection: a bias hypothesis revisited. Exp Brain Res (2016) 234:1451-8. doi:10.1007/s00221-015-4550-z

28. Roca M, Parr A, Thompson R, Woolgar A, Torralva T, Antoun N, et al. Executive function and fluid intelligence after frontal lobe lesions. Brain (2010) 133:234-47. doi:10.1093/brain/awp269

29. Iavarone A, Patruno M, Galeone F, Chieffi S, Carlomagno S. Brief report: error pattern in an autistic savant calendar calculator. J Autism Dev Disord (2007) 37:775-9. doi:10.1007/s10803-006-0190-2

30. Jeneson A, Squire LR. Working memory, long-term memory, and medial temporal lobe function. Learn Mem (2011) 19:15-25. doi:10.1101/ $\operatorname{lm} .024018 .111$

31. Lech RK, Suchan B. The medial temporal lobe: memory and beyond. Behav Brain Res (2013) 254:45-9. doi:10.1016/j.bbr.2013.06.009

32. McKhann GM, Knopman DS, Chertkow H, Hyman BT, Jack CR Jr, Claudia HK, et al. The diagnosis of dementia due to Alzheimer's disease: recommendations from the National Institute on Aging-Alzheimer's Association workgroups on diagnostic guidelines for Alzheimer's disease. Alzheimers Dement (2011) 7:263-9. doi:10.1016/j.jalz.2011.03.005

33. Galeone F, Pappalardo S, Chieffi S, Iavarone A, Carlomagno S. Anosognosia for memory deficit in amnestic mild cognitive impairment and Alzheimer's disease. Int J Geriatr Psychiatry (2011) 26:695-701. doi:10.1002/gps.2583

34. Petersen RC, Smith GE, Waring SC, Ivnik RJ, Tangalos EG, Kokmen E. Mild cognitive impairment: clinical characterization and outcome. Arch Neurol (1999) 56:303-8. doi:10.1001/archneur.56.3.303 
35. Baker LD, Frank LL, Foster-Schubert K, Green PS, Wilkinson CW, McTiernan A, et al. Effects of aerobic exercise on mild cognitive impairment: a controlled trial. Arch Neurol (2010) 67:71-9. doi:10.1001/archneurol.2009.307

36. Nagamatsu LS, Chan A, Davis JC, Beattie BL, Graf P, Voss MW, et al. Physical activity improves verbal and spatial memory in older adults with probable mild cognitive impairment: a 6-month randomized controlled trial. J Aging Res (2013) 2013:861893. doi:10.1155/2013/861893

37. van Uffelen JGZ, Chinapaw MJM, van Mechelen W, Hopman-Rock M. Walking or vitamin B for cognition in older adults with mild cognitive impairment? A randomised controlled trial. Br J Sports Med (2008) 42:344-51. doi:10.1136/bjsm.2007.044735

38. Goldman WP, Baty JD, Buckles VD, Sahrmann S, Morris JC. Motor dysfunction in mildly demented $\mathrm{AD}$ individuals without extrapyramidal signs. Neurology (1999) 53:956-62. doi:10.1212/WNL.53.5.956

39. Kemoun G, Thibaud M, Roumagne N, Carette P, Albinet C, Toussaint L, et al. Effects of a physical training programme on cognitive function and walking efficiency in elderly persons with dementia. Dement Geriatr Cogn Disord (2010) 29:109-14. doi:10.1159/000272435

40. Yágüez L, Shaw KN, Morris R, Matthews D. The effects on cognitive functions of a movement-based intervention in patients with Alzheimer's type dementia: a pilot study. Int J Geriatr Psychiatry (2010) 26:173-81. doi:10.1002/ gps. 2510

41. Jack CR, Wiste HJ, Vemuri P, Weigand SD, Senjem ML, Zeng G, et al. Brain beta-amyloid measures and magnetic resonance imaging atrophy both predict time-to-progression from mild cognitive impairment to Alzheimer's disease. Brain (2010) 133:3336-48. doi:10.1093/brain/awq277

42. Chapman SB, Aslan S, Spence JS, Defina LF, Keebler MW, Didehbani N, et al. Shorter term aerobic exercise improves brain, cognition, and cardiovascular fitness in aging. Front Aging Neurosci (2013) 5:75. doi:10.3389/ fnagi.2013.00075

43. Kempermann G, Song H, Gage FH. Neurogenesis in the adult hippocampus. Cold Spring Harb Perspect Biol (2015) 7:a018812. doi:10.1101/cshperspect. a018812

44. van Praag H, Christie BR, Sejnowski TJ, Gage FH. Running enhances neurogenesis, learning, and long-term potentiation in mice. Proc Natl Acad Sci U S A (1999) 96:13427-31. doi:10.1073/pnas.96.23.13427

45. van Praag H, Kempermann G, Gage FH. Running increases cell proliferation and neurogenesis in the adult mouse dentate gyrus. Nat Neurosci (1999) 2:266-70. doi:10.1038/6368

46. van Praag $\mathrm{H}$, Shubert T, Zhao C, Gage FH. Exercise enhances learning and hippocampal neurogenesis in aged mice. J Neurosci (2005) 25:8680-5. doi:10.1523/JNEUROSCI.1731-05.2005

47. Kempermann G, Kuhn HG, Gage FH. More hippocampal neurons in adult mice living in an enriched environment. Nature (1997) 386:493-5. doi:10.1038/386493a0

48. Kempermann G, Brandon EP, Gage FH. Environmental stimulation of 129/SvJ mice causes increased cell proliferation and neurogenesis in the adult dentate gyrus. Curr Biol (1998) 8:939-42. doi:10.1016/S0960-9822(07)00377-6

49. Heine VM, Maslam S, Joëls M, Lucassen PJ. Prominent decline of newborn cell proliferation, differentiation, and apoptosis in the aging dentate gyrus, in absence of an age-related hypothalamus-pituitary-adrenal axis activation. Neurobiol Aging (2004) 25:361-75. doi:10.1016/S0197-4580(03)00090-3

50. Clark PJ, Brzezinska WJ, Thomas MW, Ryzhenko NA, Toshkov SA, Rhodes JS. Intact neurogenesis is required for benefits of exercise on spatial memory but not motor performance or contextual fear conditioning in C57BL/6J mice. Neuroscience (2008) 155:1048-58. doi:10.1016/j.neuroscience.2008. 06.051

51. Ji JF, Ji SJ, Sun R, Li K, Zhang Y, Zhang LY, et al. Forced running exercise attenuates hippocampal neurogenesis impairment and the neurocognitive deficits induced by whole-brain irradiation via the BDNF-mediated pathway. Biochem Biophys Res Commun (2014) 443:646-51. doi:10.1016/j.bbrc.2013.12.031

52. Pereira AC, Huddleston DE, Brickman AM, Sosunov AA, Hen R, McKhann GM, et al. An in vivo correlate of exercise-induced neurogenesis in the adult dentate gyrus. Proc Natl Acad Sci U S A (2007) 104:5638-43. doi:10.1073/ pnas.0611721104

53. Lin TN, Sun SW, Cheung WM, Li F, Chang C. Dynamic changes in cerebral blood flow and angiogenesis after transient focal cerebral ischemia in rats. Evaluation with serial magnetic resonance imaging. Stroke (2002) 33:2985-91. doi:10.1161/01.STR.0000037675.97888.9D
54. Vivar C, Potter MC, van Praag H. All about running: synaptic plasticity, growth factors and adult hippocampal neurogenesis. Curr Top Behav Neurosci (2013) 15:189-210. doi:10.1007/7854_2012_220

55. Prakash RS, Voss MW, Erickson KI, Kramer AF. Physical activity and cognitive vitality. Annu Rev Psychol (2015) 66:769-97. doi:10.1146/annurevpsych-010814-015249

56. Eadie BD, Redila VA, Christie BR. Voluntary exercise alters the cytoarchitecture of the adult dentate gyrus by increasing cellular proliferation, dendritic complexity, and spine density. J Comp Neurol (2005) 486:39-47. doi:10.1002/ cne.20493

57. Vaynman S, Ying Z, Gomez-Pinilla F. Hippocampal BDNF mediates the efficacy of exercise on synaptic plasticity and cognition. Eur J Neurosci (2004) 20:2580-90. doi:10.1111/j.1460-9568.2004.03720.x

58. Pan W, Banks WA, Fasold MB, Bluth J, Kastin AJ. Transport of brain-derived neurotrophic factor across the blood-brain barrier. Neuropharmacology (1998) 37:1553-61. doi:10.1016/S0028-3908(98)00141-5

59. Ferris LT, Williams JS, Shen CL. The effect of acute exercise on serum brain-derived neurotrophic factor levels and cognitive function. Med Sci Sports Exerc (2007) 39:728-34. doi:10.1249/mss.0b013e31802f04c7

60. Griffin ÉW, Mullally S, Foley C, Warmington SA, O’Mara SM, Kelly AM. Aerobic exercise improves hippocampal function and increases BDNF in the serum of young adult males. Physiol Behav (2011) 104:934-41. doi:10.1016/j. physbeh.2011.06.005

61. Yasutake C, Kuroda K, Yanagawa T, Okamura T, Yoneda H. Serum BDNF, TNF-alpha and IL-1beta levels in dementia patients: comparison between Alzheimer's disease and vascular dementia. Eur Arch Psychiatry Clin Neurosci (2006) 256:402-6. doi:10.1007/s00406-006-0652-8

62. Laske C, Stransky E, Leyhe T, Eschweiler GW, Maetzler W, Wittorf A, et al. BDNF serum and CSF concentrations in Alzheimer's disease, normal pressure hydrocephalus and healthy controls. J Psychiatr Res (2007) 41:387-94. doi:10.1016/j.jpsychires.2006.01.014

63. Laske C, Stellos K, Hoffmann N, Stransky E, Straten G, Eschweiler GW, et al. Higher BDNF serum levels predict slower cognitive decline in Alzheimer's disease patients. Int J Neuropsychopharmacol (2011) 14:399-404. doi:10.1017/ S1461145710001008

64. Greenberg DA, Jin K. From angiogenesis to neuropathology. Nature (2005) 438:954-9. doi:10.1038/nature04481

65. Fabel K, Fabel K, Tam B, Kaufer D, Baiker A, Simmons N, et al. VEGF is necessary for exercise-induced adult hippocampal neurogenesis. Eur J Neurosci (2003) 18:2803-12. doi:10.1111/j.1460-9568.2003.03041.x

66. Carro E, Nunez A, Busiguina S, Torres-Aleman I. Circulating insulin-like growth factor I mediates effects of exercise on the brain. J Neurosci (2000) 20:2926-33.

67. Niblock MM, Brunso-Bechtold JK, Lynch CD, Ingram RL, McShane T, Sonntag WE. Distribution and levels of insulin-like growth factor I mRNA across the life span in the Brown Norway $\times$ Fischer 344 rat brain. Brain Res (1998) 804:79-86. doi:10.1016/S0006-8993(98)00645-3

68. Berg U, Bang P. Exercise and circulating insulin-like growth factor I. Horm Res (2004) 62(Suppl 1):50-8. doi:10.1159/000080759

69. Pardridge WM. Transport of insulin-related peptides and glucose across the blood-brain barrier. Ann N Y Acad Sci (1993) 692:126-37. doi:10.1111/j. 1749-6632.1993.tb26211.x

70. Trejo JL, Carro E, Torres-Aleman I. Circulating insulin-like growth factor I mediates exercise-induced increases in the number of new neurons in the adult hippocampus. J Neurosci (2001) 21:1628-34.

71. Arwert LI, Deijen JB, Drent ML. The relation between insulin-like growth factor I levels and cognition in healthy elderly: a meta-analysis. Growth Horm IGF Res (2005) 15:416-22. doi:10.1016/j.ghir.2005.09.001

72. Murialdo G, Barreca A, Nobili F, Rollero A, Timossi G, Gianelli MV, et al. Relationships between cortisol, dehydroepiandrosterone sulphate and insulin-like growth factor-I system in dementia. J Endocrinol Invest (2001) 24:139-46. doi:10.1007/BF03343833

73. Sakurai T, Amemiya A, Ishii M, Matsuzaki I, Chemelli RM, Tanaka H, et al. Orexins and orexin receptors: a family of hypothalamic neuropeptides and G protein-coupled receptors that regulate feeding behavior. Cell (1998) 92:573-85. doi:10.1016/S0092-8674(00)80949-6

74. Scammell TE, Winrow CJ. Orexin receptors: pharmacology and therapeutic opportunities. Annu Rev Pharmacol (2011) 51:243-66. doi:10.1146/ annurev-pharmtox-010510-100528 
75. Yoshida K, McCormack S, Espana RA, Crocker A, Scammell TE. Afferents to the orexin neurons of the rat brain. J Comp Neurol (2006) 494:845-61. doi:10.1002/cne.20859

76. Saper CB, Scammell TE, Lu J. Hypothalamic regulation of sleep and circadian rhythms. Nature (2005) 437:1257-63. doi:10.1038/nature04284

77. Boscia F, Passaro C, Gigantino V, Perdonà S, Franco R, Portella G, et al. High levels of GPR30 protein in human testicular carcinoma in situ and seminomas correlate with low levels of estrogen receptor-beta and indicate a switch in estrogen responsiveness. J Cell Physiol (2015) 230:1290-7. doi:10.1002/ jcp. 24864

78. Franco R, Zappavigna S, Gigantino V, Luce A, Cantile M, Cerrone M, et al. Urotensin II receptor determines prognosis of bladder cancer regulating cell motility/invasion. J Exp Clin Cancer Res (2014) 33:48. doi:10.1186/ 1756-9966-33-48

79. Marra L, Cantile M, Scognamiglio G, Perdonà S, La Mantia E, Cerrone $M$, et al. Deregulation of HOX B13 expression in urinary bladder cancer progression. Curr Med Chem (2013) 20:833-9. doi:10.2174/092986713805076658

80. Sakurai T, Mieda M. Connectomics of orexin-producing neurons: interface of systems of emotion, energy homeostasis and arousal. Trends Pharmacol Sci (2011) 32:451-62. doi:10.1016/j.tips.2011.03.007

81. Messina G, Viggiano A, Tafuri D, Palmieri F, De Blasio S, Messina A, et al. Role of orexin in obese patients in the intensive care unit. J Anesth Clin Res (2014) 5:395. doi:10.4172/2155-6148.1000395

82. Messina G, Monda V, Moscatelli F, Valenzano AA, Monda G, Esposito T, et al. Role of orexin system in obesity. Biol Med (Aligarh) (2015) 7:248. doi:10.4172/0974-8369.1000248

83. Messina G, Palmieri F, Monda V, Messina A, Dalia C, Viggiano A, et al. Exercise causes muscle GLUT4 translocation in an insulin-independent manner. Biol Med (Aligarh) (2015) 1:006. doi:10.4172/0974-8369. $1000 \$ 3007$

84. Chieffi S. Orexinergic system dysregulation in depression. J Psychiatry (2016) 20:e107. doi:10.4172/2378-5756.1000e107

85. Wayner MJ, Armstrong DL, Phelix CF, Oomura Y. Orexin-A (hypocretin-1) and leptin enhance LTP in the dentate gyrus of rats in vivo. Peptides (2004) 25:991-6. doi:10.1016/j.peptides.2004.03.018

86. Akbari E, Naghdi N, Motamedi F. The selective orexin 1 receptor antagonist SB-334867-A impairs acquisition and consolidation but not retrieval of spatial memory in Morris water maze. Peptides (2007) 28:650-6. doi:10.1016/j. peptides.2006.11.002

87. Zhao X, Zhang Rx, Tang S, Ren Yy, Yang Wx, Liu Xm, et al. Orexin-A-induced ERK $1 / 2$ activation reverses impaired spatial learning and memory in pentylenetetrazol-kindled rats via OX1R-mediated hippocampal neurogenesis. Peptides (2014) 54:140-7. doi:10.1016/j.peptides.2013.11.019

88. Martins PJ, D’Almeida V, Pedrazzoli M, Lin L, Mignot E, Tufik S. Increased hypocretin-1 (orexin-a) levels in cerebrospinal fluid of rats after short-term forced activity. Regul Pept (2004) 117:155-8. doi:10.1016/j. regpep.2003.10.003

89. Wu MF, John J, Maidment N, Lam HA, Siegel JM. Hypocretin release in normal and narcoleptic dogs after food and sleep deprivation, eating, and movement. Am J Physiol Regul Integr Comp Physiol (2002) 283:R1079-86. doi:10.1152/ajpregu.00207.2002

90. Kiyashchenko LI, Mileykovskiy BY, Maidment N, Lam HA, Wu MF, John J, et al. Release of hypocretin (orexin) during waking and sleep states. J Neurosci (2002) 22:5282-6.

91. Messina G, Di Bernardo G, Viggiano A, De Luca V, Monda V, Messina A, et al. Exercise increases the level of plasma orexin A in humans. J Basic Clin Physiol Pharmacol (2016) 27:611-6. doi:10.1515/jbcpp-2015-0133

92. Monda M, Messina G, Mangoni C, De Luca B. Resting energy expenditure and fat-free mass do not decline during aging in severely obese women. Clin Nutr (2008) 27:657-9. doi:10.1016/j.clnu.2008.04.005

93. Monda M, Messina G, Scognamiglio I, Lombardi A, Martin GA, Sperlongano P, et al. Short-term diet and moderate exercise in young overweight men modulate cardiocyte and hepatocarcinoma survival by oxidative stress. Oxid Med Cell Longev (2014) 2014:131024. doi:10.1155/2014/131024

94. Moscatelli F, Messina G, Valenzano A, Petito A, Triggiani AI, Ciliberti MAP, et al. Relationship between RPE and blood lactate after fatiguing handgrip exercise in Taekwondo and sedentary subjects. Biol Med (Aligarh) (2015) S3:008. doi:10.4172/0974-8369.1000S3008

95. Valenzano A, Moscatelli F, Triggiani AI, Capranica L, De Ioannon G, Piacentini MF, et al. Heart-rate changes after an ultraendurance swim from Italy to Albania: a case report. Int J Sports Physiol Perform (2016) 11:407-9. doi:10.1123/ijspp.2015-0035

96. Tsunematsu T, Yamanaka A. The role of orexin/hypocretin in the central nervous system and peripheral tissues. Vitam Horm (2012) 89:19-33. doi:10.1016/ B978-0-12-394623-2.00002-0

97. Kastin AJ, Akerstrom V. Orexin A but not orexin B rapidly enters brain from blood by simple diffusion. J Pharmacol Exp Ther (1999) 289:219-23.

Conflict of Interest Statement: The authors declare that the research was conducted in the absence of any commercial or financial relationships that could be construed as a potential conflict of interest.

Copyright (C) 2017 Chieffi, Messina, Villano, Messina, Valenzano, Moscatelli, Salerno, Sullo, Avola, Monda, Cibelli and Monda. This is an open-access article distributed under the terms of the Creative Commons Attribution License (CC BY). The use, distribution or reproduction in other forums is permitted, provided the original author(s) or licensor are credited and that the original publication in this journal is cited, in accordance with accepted academic practice. No use, distribution or reproduction is permitted which does not comply with these terms. 